2017-09-01

'Supporting professional doctorate

women students through identity change and turbulent times: who cares?'

Webber, Louise

http://hdl.handle.net/10026.1/10166

10.1080/02643944.2017.1363812

Pastoral Care in Education

Taylor \& Francis (Routledge)

All content in PEARL is protected by copyright law. Author manuscripts are made available in accordance with publisher policies. Please cite only the published version using the details provided on the item record or document. In the absence of an open licence (e.g. Creative Commons), permissions for further reuse of content should be sought from the publisher or author. 
"This is an Accepted Manuscript of an article published by Taylor \& Francis in Pastoral Care in Education on 01/09/17 , available online: 01/09/17 http://www.tandfonline.com/ 10.1080/02643944.2017.1363812."

Supporting Professional Doctorate women students through identity change and turbulent times: Who cares?

Dr Louise Webber

Early Childhood Studies, Plymouth University, Plymouth, United Kingdom.

Plymouth Institute of Education, Plymouth University, Drake Circus, Plymouth, Devon. PL4 8AA, 01752 585354, louise.webber4@plymouth.ac.uk.

Dr Louise Webber is a Lecturer in Early Childhood Studies at Plymouth University. She has a particular interest in mature women learners in higher education and also in looked after and adopted children. 


\title{
Supporting Professional Doctorate women students through identity change and turbulent times: Who cares?
}

\author{
Professional doctorates are designed to enable students to blend their doctorate level \\ study with their working lives. During the course of their studies women undergo \\ identity change and transformation as their perspectives change, this has knock on \\ effects at home and at work. Women students, who are mothers, also have to balance \\ and juggle their studies with the needs of their family, this happens with various \\ degrees of success.
}

This paper focuses on the stories of six female students who have faced turbulent times during their professional doctorate programme. Examples of 'turbulence' include relationship breakdown, ill health and conflict at work because of their changing identity. It uses qualitative methods of focused interviews, using a mind mapping technique to illuminate their experiences. An interpretivist, narrative approach using Mezirow's theory of transformation explores the tensions that occur for some women during their studies and considers the role of care in the supervisory relationship.

Findings show that when women face turbulence there can be barriers that prevent them from turning to their supervisor for support. During a professional doctorate programme students can be at different points on the continuum of coping or struggling with their studies, home and professional life. Although students recognise they have a responsibility to be resilient and manage any difficulties they may have, they seek acknowledgment and empathy from their supervisor within the boundaries of a supportive, non-hierarchal relationship.

Keywords: professional doctorate, women, identity, care, supervisor

\section{Introduction}

Studying a professional doctorate as a female student with family responsibilities can be empowering, life changing and self-fulfilling but it can also become a difficult, tense experience for women. Being a mother or carer can have 'profound implications for doctorallevel studies' (Brown and Watson, 2010, p.385). Studying as a part time learner, balancing 
family life, study and often a busy career can be a juggling act of roles, responsibilities and deadlines.

The complexities of juggling higher education (HE) studies and family life for women students are well documented (Edwards, 1993; Merrill, 1999; Parr, 2000; Pascall and Cox, 1993; Webber 2015; Webber 2017). These difficulties are often portrayed as unique to women and different to men (Edwards, 1993; Merrill, 1999). Although there is a greater appreciation for diversity in family life (Chambers, 2012) since the publication of some of these earlier studies, gender inequalities in terms of women's earnings (ONS, 2014) and unequal gender distribution of domestic duties are still prevalent issues for women (Chambers, 2012; The Fatherhood Institute, 2016). This paper adds to the debate on the complexities of studying HE and juggling family life and considers this from the perspective of female professional doctorate students as this is an area that in under-represented in previous research.

Wellington and Sikes (2006) highlight the pressure of 'spinning plates' and juggling multiple roles which can lead to family breakdown as families struggle to adjust to the changes caused by the reality of doctorate studies. Mothers on a professional doctorate programme often choose to do this at a time when they face 'practical, emotional and financial demands', (Wellington and Sikes, 2006, p.731). Therefore the strain on the family unit can become greater.

\section{Identity change and transformation: personal and professional}

Coupled with the difficulties women may face in juggling their studies they also experience identity change. Identity change and transformation is to be expected as $\mathrm{HE}$ is viewed as an empowering space to construct and change self-perception (Parr, 2001). Developing a questioning and critical approach (Wellington and Sikes, 2006), leads to personal growth 
through confidence development and raised self-esteem (Baker and Pifer, 2015). Difficulties within both their professional and personal life can then occur as sometime those closest to them struggle to adapt to the changes.

Transformation theory (Mezirow, 1991) is useful in understanding why women begin to question and redefine previous duties and obligations held within previous positions or roles (Harré and Lagenhove, 1999). Heightened reflection and an analysis of socially constructed ideals, values and beliefs and assumptions are challenged in light of new educational experiences (Mezirow, 1991). This can be an emotionally intense and uncomfortable experience (Mezirow, 2000) for some women as they grapple with coming to terms with their new identity (Webber, 2017).

Professional doctorates are designed for those working to enable them to make significant links between their professional experience and knowledge development (Chiteng Kot and Hendel, 2012). Professional identity can be transformed, as students begin to see their workplace role in a new light, which leads to workplace theorising through the development of conceptual ideas (Pratt, Tedder, Boyask and Kelly, 2015). However for some doctoral students their studies are viewed in a negative light by their employers or colleagues as they are perceived as being too academic and 'divorced from pragmatic realities', (Wellington and Sikes, 2006, p.731).

Higher Education study is emotionally intense for many women students (Jantaa, Lugosib and Brown, 2014; Kahu et al. 2015) as they can lack confidence in their own abilities. They feel guilty when they juggle their studies and family life and try to manage work. Straining to cope with the emotional demands from the family and balancing their multiple roles (Wellington and Sikes, 2006) can be exhausting and lead to tension and stress. Women are often responsible for regulating the emotional needs of their family (Lynch, 
Lyons and Cantillon, 2007). Therefore trying to manage their own emotions, caused by the complexities of studying, can be a difficult and sometimes lonely journey (Janta, Lugosi and Brown, 2014).

\section{Issues of care: barriers to confiding issues of tension to a supervisor}

When women experience these struggles and tensions who can they rely on for support? There are two issues here, firstly is it the role of the academy to care, secondly where do students seek care and empathy for any difficulties they may experience? Should using a relational approach which fosters caring and the emotional well-being of students, not just the academic self, be the moral duty of teaching staff (Gholami and Tirri, 2012) or is it a wider structural issue of care?

The performance driven Cartesian ethos of the institution (Grummell, Devine and Lynch, 2009), which includes the perception of a culture of 'carelessness' (Lynch, 2010), can act as a barrier that prevents women students from admitting any difficulties within the academy. A 'lack of attention given to issues of care and interdependency' in HE (Grummell, Devine and Lynch, 2009, p.204) can result in women's needs being unnoticed. When the affective aspects of education are overlooked in favour of academic achievements (Kahu et al., 2015), scholarly work is then viewed as separate to emotional thought (Lynch, 2010). Seeing the academic and personal as two separate entities can result in the holistic needs of students being overshadowed by issues of performativity. Although I believe the issue of care is a wider structural issue, for the purpose of this article I will focus on the supervisor providing some form of care as they are the first point of academy contact for professional doctorate students who wish to share any tensions they are experiencing.

Often doctoral students don't expect to receive emotional support from their supervisor (Janta, Lugosi and Brown, 2014) which stops them from asking for help. This 
could be because of their awareness of the increasing workload of an academic (Kolsaker, 2008) or their belief that learning is more of a cognitive than emotional process (Christie et al. 2008). If supervisors are viewed as successful academics, 'uncumbered by caring', (Lynch, 2010, p.63) then they may appear as unapproachable sitting in their 'ivory tower' of academia. A woman's lack of confidence in her doctorate level academic abilities may result in her perceiving that her supervisor see her as deficient (Kahu et al., 2015), this can affect the supervisory/student relationship. As HE learners are expected to be 'autonomous and rational' (Lynch, 2010, p.3), women students can appear reluctant to admit struggles in their personal lives as this can be seen as admitting to failure (Goodall et al., 2017). Although developing quality caring relationships with students is an avenue supervisors can take, boundaries can become crossed when professional relationships merge with friendship (Chory and Offstein, 2016). Therefore understanding the expectations and boundaries from both a student and supervisor viewpoint are important when developing pastoral care relationships (Janta, Lugosi and Brown, 2014).

Willingness to turn to a supervisor during times of turbulence is often linked to the strength of the relationship and whether the student feels that they fit into the professional doctorate environment (Baker and Pifer, 2015). Although Baker and Pifer (2015) advocate building supervisory relationships with individuals with similar experiences or traits (e.g. same sex supervisors) this is contested by Brown and Watson (2010) who found that the family or domestic life of the supervisors was more important than gender when showing empathy or care. A lack of relationship or support from a supervisor can result in a lack of motivation to continue or succeed at the doctorate (Baker and Pifer, 2015).

In response to the issues raised in this literature review, this paper will explore:

- What are the emotional and practical issues that women experience on a professional doctorate programme? 
- $\quad$ Are there any barriers stopping women from confiding in their supervisors?

- Whose responsibility is it to care?

\section{Methodology}

This small scale interpretivist study used narrative methodology of focused interviews using mind mapping interview techniques. The strengths of the narrative approach is that experience is understood (Clandinin and Connelly, 2000) using the unique voices of participants. It is important to acknowledge that my own standpoint and experiences of being a mother that studies affected my interpretation and understanding of the themes raised in this research. This gave me both an insider and outsider perspective (Mercer, 2007). As an insider as I could identify with some of the issues raised by the women, but I was also considered an outsider as each experience is different. I had to ensure that my own experiences and feelings did not surface or over whelm the study (Farnsworth, 1997). Having this perspective gave me empathy with the women and enabled a rapport to be developed quickly which facilitated open discussion.

\section{Participants}

The full study was based on 11 women on Professional Doctorate programmes in England. An email was sent through the Professional Doctorate Network to gather potential participants. Although a small sample size can be constraining, like Waller (2006), I maintain that this is still sufficient to gather meaningful data. Although this type of study is data rich it must be acknowledged that using such few cases is a limitation and generalisations cannot be made from these findings.

The participants were all self-selecting but had to meet the criteria of being female, over 25 years of age, having a long term partner over 2 years and either children under 18 or someone dependent on them for care. All participants were given the outline of the study and agreed 
the ethical protocol before the interviews commenced. All participants were given a pseudonym to protect their identity.

A profile of participants is as follows:

Carolyn, aged 47, married to John, together for 23 years (6 children aged 3-19)

Emily, aged 46, single mum, together for over 10 years, separated for three and divorced whilst on the Professional Doctorate (2 children aged 9 and 10)

Helen, aged 49, married to Michael, together for 18 years (3 children aged 10 and 18+)

Lou, aged 49, married to Matthew, together for 26 years ( 2 children aged 7 and 9)

Susan, aged 53, married to Paul, together for 28 years (4 generations living in one house, including 2 adult children, a grandchild aged 6 and an elderly parent)

Vicky, aged 57, partner to John, together for 15 years (full time carer for partner)

\section{Phase 1}

Participants were invited to mind map their responses to the following 4 statements prior to a focused interview:

- ME - Identity, roles before the Professional Doctorate experience

- Identity, roles during or after the Professional Doctorate experience

- Changes/transformation - what has changed, why?

- How has this impacted on your different relationships?

The focused interview was participant led based around their responses to the mind mapping task which encouraged open discussion and a sensitive approach due to the nature of the topics discussed.

\section{Phase 2}


6 students were selected from the original cohort for this paper, the selection was based on finding a range of students who had faced and overcome turbulent times within their professional doctorate studies. Examples of 'turbulence' include relationship breakdown, dealing with guilt over juggling family life and studies, ill health and conflict at work because of their changing identity. These students were then asked 4 questions via an emailed questionnaire focusing on the topic of supervisory care and support.

\section{Analysis}

The interviews and questionnaires were analysed and coded using a thematic framework analysis approach. These themes focused on transformation (family and professional identity) and the effects of this on home/work/study life balance.

\section{Findings}

The interviews highlighted a number of key areas which contribute to the literature in enabling the themes of identity change, work/family balance and issues of supervisory care to be illuminated.

\section{Family identity}

Some students saw their identity as mainly motherhood focused:

I think my overwhelming sense of identity would have been a mum with children, and that was the core of it and was the central unchanging part of my identity with my professional role around the outside of that and perhaps seeping into any cracks. (Lou)

We are now in the position where there are four generations in the house ... and I think that's why I've had to go part-time [work] just because of the conflict between what the family needs and what I need, it's just more difficult really (Susan)

Changing how you act as a mother or how you are positioned can cause tension at home (Brown and Watson, 2010; Webber, 2017). Tensions can be caused by a number of factors 
during a professional doctorate (see also Brown and Watson, 2017; Wellington and Sikes, 2006). These factors include identity change, being perceived by family members to put their study first, conflicting needs between home life and study life and the pressures of assignment deadlines. This was particularly pertinent for those in more gender biased households who considered themselves more family/motherhood orientated than work/career focused.

It's very difficult to juggle those balls and you always feel guilty about whichever area you're not doing. (Emily)

I think I'm struggling to find the right way to actually find that balance. (Susan) Guilt is a strong emotion that is experienced by women students (Brooks, 2015; Edwards 1993; Webber, 2017) as they are often seen as responsible for organising their study needs around the family (Edwards, 1993). Women are often socially constructed as having the main responsibility for childcare and housework (Brooks, 2015; The Fatherhood Institute, 2016). Guilt arises when the professional doctorate is perceived as being put before the family. The career/work orientated mothers who had equal or lesser responsibilities for childcare and household tasks also felt the guilt of conflicting priorities demonstrating that these pressures can be experienced by all female professional doctorate students.

I think sometimes doing the EdD study I feel guilty I'm not spending that time with my family, and what makes me think I'm good enough to do an EdD and I should be just spending time with my family, and sometimes there's that thought going through my head ... feeling conflicted, that sometimes I feel that guilt as a mum that I'm being a bad mum. (Carolyn)

According to Longhurst, Hodgetts and Stolte (2012) guilt is highly gendered as women find it hard to separate themselves from their children and maintain a separate identity. As women try to juggle the competing demands of their HE studies and family life, feelings of being torn in two are quite common (Longhurst, Hodgetts and Stolte, 2012, Webber, 2017). 
Therefore feelings of guilt can surface when women feel that competing interests result in them falling short of providing adequate care for their family (Brook, 2015; Noddings, 2013).

\section{Professional Identity}

I think my identity unfortunately, and I'm not that happy about it, is quite heavily focused around work. (Helen)

My sense of identity really came from my role as a professional, from my role as a teacher ... and I think it's something very important to me. (Carolyn)

Identity transformation or the pressures of the professional doctorate also affect a woman's professional identity. Balancing study, work or family can be difficult but coping with changing perspectives (Mezirow, 1991) which conflict with cultural practices at work can cause further tensions (Pratt et al., 2015).

So whilst I've learnt more during the EdD, it's not necessarily been a comfortable process it's been quite uncomfortable, almost like somebody's trying to pull the rug from under you and shake it a bit, because I recognise things before that I wouldn't have recognised. (Carolyn)

Colleagues can offer support (though this can wane) but they also may feel threatened by the changed knowledge base or perceived raised status of their studying colleague.

The deputy head found me a threat [when Emily started her professional doctorate] and it didn't matter how many times I told him I wasn't interested in becoming a deputy head ... one of the reasons I left [the job] was because he was becoming intolerable and I felt he tried to step in and sabotage my research interview. (Emily)

These types of tensions at work can come as a surprise to women as they sometimes materialise further on in the doctorate journey:

The balance is quite difficult one and because it's with a very hectic professional life as well ... and I think when work were being very supportive it was easier to balance everything ... Initially on the taught stages they gave me time off work to go to the Friday ... they've been quite awkward about things since the taught stages ... (Carolyn) 
Some women, who initially were balancing work and study life quite satisfactorily, may find that this changes during the course of the programme (see also Figure 2).

\section{Summary of the main emotional tensions for women students}

These tensions at home and professionally can cause a number of difficulties for women students (see Figure 1).

\section{Figure 1: Emotional tensions that affect female professional doctorate students}

These difficulties can come at different points in the course and at differing levels of a continuum (see Figure 2).

Figure 2: A continuum of the levels of a student's ability to manage the demands of study/home/work life balance

I think the first couple of years were fine, but then again life has encroached ... it's just more difficult really... I think in terms of my self-confidence it has made me feel, there's two parts to it; one the one hand I feel a lot more confident ... I feel like I'm cleverer than I thought I was ... But I think on the other hand, because I'm in a school that doesn't seem to recognise ... something that's any different from the job [Professional Doctorate], I do feel quite frustrated. (Susan)

These transformations can be emotionally intense (Mezirow, 2000) as students grapple with their changing identity and the impact on others (Webber, 2017).

...it's the drudgery of being a parent and the house and things starting to fall down round your ears, and the front lawn looking like a jungle, big piles of washing and nobody's got any clean underpants, which I can laugh about now but when work is so, so intense, all those things slip off the radar for me. (Lou)

Some students find it hard to be open about this but then get to a point where they can no longer hide it and then seek help:

And I think until the health issues I was able to have this professional life, family life and the study ... with the illness it's just complicated everything so much more and it's not as simple as it once was to juggle those three separate things ... to say, 'Actually I needed a deferral', was really, really hard and that in many ways felt like a bit of a failure. (Carolyn)

Whose responsibility is it to care? 
I do not feel that it is my supervisor's job to help me with my private life, but when my private life has prevented me from doing the work, then I have felt that I need to communicate this rather than trying to hide it. (Emily)

Trying to manage these difficulties alongside of juggling the professional doctorate, work and family life can be overwhelming for doctorate students as they try to make 'productive use of tiny amounts of time', (Wellington and Sikes, 2006, p.731). Admitting these difficulties to others can be hard particularly if friends or family members don't understand their reasons for starting the programme or the tensions they experience during their journey (see also Webber, 2017).

They [friends] don't get it so I don't tend to talk about it that much, I can see them glaze over when I start talking about it. (Lou)

So we [partner] had this disagreement and then when I actually got onto the course ... he said, well, it's good for you but no-one else, so his whole attitude changed. (Emily)

When students experience these tensions they are faced with the dilemma of coping alone or turning to others for support.

Ifeel it is the student's place to manage that with support that is available ... so I think it is part of their role [supervisor] when the need arises, but not their responsibility. The student must do what they can, but should not hide from the supervisor if things are getting to the point where the work will suffer. (Emily)

Deciding whether to confide in their supervisor can be dependent on many factors such as the strength of the relationship (Baker and Pifer, 2015), whether they perceive their supervisor as caring (Lynch, 2010) or whether they are brave enough to admit that they may not be coping with their studies, professional and family life (Goodall et al., 2017).

\section{What do students want from their supervisor?}

Although this study focuses on a small sample size there were 3 themes of note that illuminate factors that can affect the quality of the student/supervisor relationship (see Figure $3)$. 


\section{Figure 3: Factors that support the student/supervisor relationship}

The perceived hierarchical relationship between the student and supervisor can facilitate or prevent caring interactions:

And one of the things that we are finding particularly difficult as a group is when we get an email that says you didn't turn up, and you think do you know what guilt I went through, I didn't turn up but I agonised over that choice ... They haven't got it ... but as a mature working postgraduate, a doctoral person, you never not turn up because you're lazy. (Emily)

The professional doctorate is a unique part time programme which enables the women to juggle the many facets of the roles alongside the taught sessions, yet this does not come without its costs as it can be emotionally demanding (Wellington and Sikes, 2006). When women are experiencing tension and conflict in their personal life, professional life or with ill health they would like some understanding from their supervisors acknowledging the pressure that they are under.

When real family life stuff happens you have to divert your priorities, and I think at that point it became just difficult. (Susan)

Flexibility, understanding and empathy can be provided by supervisors in many different circumstances but there can be a disparity in the level of support offered.

I think it depends on the tutor to be honest; I'm very, very lucky with my supervisor ... but there are other lecturers which don't seem to get it [complexities of juggling studies, family life and work]. (Emily)

The strength of the supervisor/student relationship (Baker and Pifer, 2015) or some shared understanding and experience of domestic or family life (Brown and Watson, 2010) affects support. But there are other factors to consider such as the supervisor's values and beliefs concerning the nature of the supervisory relationship. Cartesian values that lean towards an ethos of performance management (Grummell, Devine and Lynch, 2009) or a belief that students should be completely autonomous (Lynch, 2010) may result in a supervisor being 
more detached or adopting a policy driven signposting response to difficulties. Being overwhelmed by performance management targets (Smith, 2017) can also be a contributing factor resulting in increased stress or a lack of time (Kolsaker, 2008).

I spoke to one of my tutors about my health difficulties related to deterioration in my medical condition. Their response was to point me in the direction of Mitigating Circumstances. Really what I needed was them to show what I would describe as greater empathy. (Vicky)

\section{Negotiating responsibilities and boundaries in the supervisory/student relationship}

Janta, Lugosi and Brown (2014) recognise the importance of creating pastoral boundaries between students and supervisors. Negotiating how much support to offer and when to encourage autonomy and independence that is expected of doctoral learners can be a complex task. Encouraging problem solving skills in students is one aspect that can be developed:

In my case I think that my supervisor/tutor has a duty of care towards me ... probably the greatest care that my tutor can show is to help me problem-solve when I am having difficulties in managing the emotional turmoil that is in my life. (Vicky)

It is important for students to recognise their responsibilities in developing emotional resilience but equally important is for supervisors to see students holistically and acknowledge the affective aspects of learning, not just the academic (Kahu et al. 2015)

I think a good supervisor will care 'about' their students, but especially with distance learning, the contact with the supervisor is much more sporadic and I don't see how the supervisor can (or why they should) care for the student. However, if the student expresses difficulties or concern, then the supervisor is the person they should be able to go to ... however, I think that it is the student's responsibility to ensure that they build up a network of support from family, friends and other students.... (Emily)

\section{Discussion}

Throughout this paper I have illuminated the difficulties women with caring responsibilities experience when on a professional doctorate programme. As women transform their perspectives and values (Mezirow, 1991), so tensions can arise at home, at work, with relationships or as their identity changes (Webber, 2017; Wellington and Sikes, 2006). 
Emotional pressures can also lead to stress and ill health causing additional pressures for women to contend with.

I have argued that different levels of turbulence can arise at different points on the programme and those students who may have been coping initially may struggle as time commences. It is important for supervisors, course leaders and policy makers to recognise that different students will be at different points on the continuum of coping or struggling with their studies, home and professional life (see Figure 2). This will change at different stages on their doctorate journey as various pressures and tensions surface or as their identity and knowledge base develops. Creating opportunities for pastoral discussions within and outside of the taught spaces is important. However, it is also essential to recognise the demands and stress levels for academics (Kolsaker, 2008) and consider how these spaces and opportunities can be built into their current workload and teaching timetable. Opening a dialogue with students considering the roles, responsibilities and professional boundaries of both students and supervisors (see Goodall et al., 2017; Janta, Lugosi and Brown, 2014) is also crucial in providing care within the relationship.

The arguments raised have concerned whose responsibility it is to manage these emotional strains or tensions: student or supervisor? Whose duty is it for care? Although female students acknowledge that it is their responsibility to be emotionally resilient, independent and autonomous, having supervisors who are aware of the turbulence they may experience and offer some form of support seems to be a common theme.

\section{Conclusion}

The literature alludes to the fractured nature of women's lives which results in tensions for professional doctorate students as they complete their studies (see Brown and Watson, 2010; Wellington and Sikes, 2006). Female professional doctorate students are all different, the 
complex nature of balancing their home and work life makes studying problematic. My research has shown two key points of note:

Firstly, women students experience stress at different points on their programme due to their caring responsibilities and changing identity. Undertaking research can be emotionally draining as their perceptions are challenged (Mezirow, 2000) and their abilities stretched, this can cause vulnerability. Sometimes students hide any turmoil they are experiencing, some students are willing to share this and turn to their supervisor (as first point of contact) for support. Professional doctorate students may choose to hide any struggles they experience due to a perceived hierarchal relationship or due to the nature of a professional doctorate they may lack opportunities to develop connections with their supervisor. Questions need to be addressed at academy level in terms of who supports the supervisor, what training do they have in signposting students on or understanding the tensions they are experiencing?

Secondly, issues of care should not just rest on the supervisor alone. Having academy structures in place to facilitate relationships which have the capacity to recognise, empathise and discuss any tensions that occur is important. Finding a balance between performance driven Cartesian values (Grummell, Devine and Lynch, 2009) and an approach that focuses on the affective dimensions is something to be strived towards. Acknowledging that the role of care is part of the academy's duty, seeing student's holistically rather than just academically (Kahu et al., 2015), even at doctorate level, is important in supporting students in their journey to success.

This study has limitations as it is based on a small number of participants and lacks data from the perspective of the supervisor. However my intention was to use this article to raise awareness of the complexities of professional doctorate studies for women with caring responsibilities and to facilitate a debate concerning the role of the academy and the supervisor in providing care for any women students experiencing turbulence. 


\section{References}

Baker, V.L. and Pifer, M.J. (2015). Antecedents and outcomes: theories of fit and the study of doctoral education. Studies in Higher Education, 40 (2), 296-310.

Brooks, R. (2015). Social and spatial disparities in emotional responses to education: feelings of 'guilt' among student-parents. British Educational Research Journal, 41 (3), 505519.

Brown, L. and Watson, P. (2010). Understanding the experiences of female doctoral students. Journal of Further and Higher Education. 34 (3), 385-404.

Chambers, D. (2012). A Sociology of Family Life. Cambridge: Polity Press.

Chiteng Kot F. and Hendel, D.D. (2012). Emergence and growth of professional doctorates in the United States, United Kingdom, Canada and Australia: a comparative analysis. Studies in Higher Education, 37 (3), 345-364.

Chory, R.M. and Offstein, E.H. (2016). Your Professor Will Know you as a Person: Evaluating and Rethinking the Relational Boundaries Between Faculty and Students. Journal of Management Education, 1-30.

Christie, C., Tett, L., Cree, V.E., Hounsell, J. and McCune, V. (2008). 'A real rollercoaster of confidence amd emotions': learning to be a university student. Studies in Higher Education, $33(5), 567-581$.

Clandinin, D.J. and Connelly, F.M. (2000). Narrative Inquiry. Experience and Story in Qualitative Research. California: The Jossey-Bass Incorporated Publishers.

Edwards, R. (1993). Mature Women Students: Separating or Connecting Family and Education. Taylor and Francis: London.

Farnsworth, E.B. (1997). Reflexivity and Qualitative Family Research: Insider's Perspectives in Bereaving the Loss of a Child. Marriage and Family Review, 24 (3-4), 399-415.

Gholami, K. and Tirri, K. (2012). Caring Teaching as a Moral Practice: An Exploratory Study on Perceived Dimensions of Caring Teaching. Education Research International. 954274, 1-8.

Goodall, H., Huggins, V., Webber, L. and Wickett, K. (2017 - under review). From Student to Graduate: Four Learners' Perspectives of the Professional Doctorate Journey. Management in Education (MiE)

Grummell, B., Devine, D. and Lynch, K. (2009). The care-less manager: gender, care and new managerialism in higher education. Gender and Education, 21 (2), 191-208.

Harré R. and van Lagenhove, L. (1999). The Dynamics of Social Episodes. In Harré, R. and van Langenhove, L. (Eds.) Positioning Theory (pp.1-13). Oxford: Blackwell Publishers.

Janta, H. Lugosi, P. and Brown, L. (2014). Coping with loneliness: A netnographic study of doctoral students. Journal of Further and Higher Education, 38 (4), 553-571. 
Kahu, E., Stephens, C., Leach, L. and Zepke, N. (2015). Linking academic emotions and student engagement: mature-aged distance students' transition to university. Journal of Further and Higher Education, 39 (4), 481-497.

Kolsaker, A. (2008). Academic professionalism in the managerialist era: a study of English universities. Studies in Higher Education, 33 (5), 513-525.

Longhurst, R., Hodgetts, D. \& Stolte, O. (2012). Placing guilt and shame: lone mothers' experiences of higher education in Aotearoa New Zealand. Social \& Cultural Geography, 13 (3), 295-312.

Lynch, K., Lyons, M. and Cantillon, S. (2007). Breaking silence: educating citizens for love, care and solidarity. International Studies in Sociology of Education, 17 (1-2), 1-19.

Lynch, K. (2010). Carelessness: A hidden doxa of higher education. Arts and Humanities in Higher Education, 9 (54), 54-67.

Mercer, J. (2007). The challenges of insider research in educational institutions: wielding a double edged sword and resolving delicate dilemmas. Oxford Review of Education, 33 (1), 117.

Merrill, B. (1999). Gender, Change and Identity: Mature Women Students in University. Aldershot: Ashgate.

Mezirow, J. (1991). Transformative Dimensions of Adult Learning. California: Jossey-Bass Inc.

Mezirow, J. (2000) Learning as Transformation: Critical Perspectives on a Theory in Progress. San Francisco: Jossey-Bass.

Noddings, N. (2013). Caring. A Relational Approach to Moral Education.2nd edn. London: California Press.

Office for National Statistics (ONS) (2014). Annual Survey of Hours and Earnings, 2014 Provisional Results. Date of Publication 19 November 2014. Available at: http://www.ons.gov.uk/ons/publications/re-reference-tables.html?edition=tcm\%3A77-337425 (Accessed: 6 December 2014).

Parr, J. (2000). Identity and Education: The Links for Mature Women Students. Aldershot: Ashgate.

Pascall, G. and Cox, R. (1993). Women Returning to Higher Education. SRHE: Buckingham.

Pratt, N, Tedder, M. Boyask, R. and Kelly, P. (2015). Pedagogic relations and professional change: a sociocultural analysis of students' learning in a professional doctorate. Studies in Higher Education, 40 (1), 43-59.

Smith. J. (2017). Target-setting, early-career academic identities and the measurement culture of UK higher education. Higher Education Research \& Development, 36 (3), 597-611.

The Fatherhood Institute (2016) 2016 Fairness in Families Index, Capstone Project. Available at: http://www.fatherhoodinstitute.org/wp- 
content/uploads/2016/06/FINALFatherhood-Institute-Capstone-FiFI-2016.pdf (Accessed: 14 June 2016).

Waller, R. (2006). I don't feel like 'a student', I feel like 'me'!': the over-simplification of mature learners' experience(s). Research in Post-Compulsory Education, 11 (1): 115-130.

Webber, L. (2015). Mature Women and Higher Education: Reconstructing Identity and Family Relationships. Research in Post Compulsory Education, 20 (2), 208-226.

Webber, L. (2017). Juggling Higher Education Studies and Family Life. London: UCL IOE Press.

Wellington, J. and Sikes, P. (2006). 'A doctorate in a tight compartment': why do students choose a professional doctorate and what impact does it have on their personal and professional lives? Studies in Higher Education, 31 (6), 723-734.

WORD COUNT 5,596-(excludes abstract and key words) 